\title{
A COMPARISON OF THREE POPULAR TEST METHODS FOR DETERMINING THE SHEAR MODULUS OF COMPOSITE MATERIALS
}

\author{
H. Ho, M.Y. Tsai, J. Morton \\ Department of Engineering Science and Mechanics \\ Virginia Polytechnic Institute and State University \\ Blacksburg VA 24061-0219 \\ and \\ G. L. Farley \\ US Army Aerostructures Directorate \\ NASA Langley Research Center \\ Hampton, VA 23665-5225
}

\begin{abstract}
Three popular shear tests - the $10^{\circ}$ off-axis, the $\pm 45^{\circ}$ tensile and the Iosipescu specimen tested in the modified Wyoming fixture - for shear modulus measurement are evaluated for a graphite-epoxy composite material system. A comparison of the shear stress-strain response for each test method is made using conventional strain gage instrumentation and moire interferometry. The uniformity and purity of the strain fields in the test sections of the specimens are discussed, and the shear responses obtained from each test technique are presented and compared. For accurate measurement of shear modulus, the $90^{\circ}$ Iosipescu specimen is recommended.
\end{abstract}

\section{INTRODUCTION}

The in-plane shear modulus $G_{12}$ of a unidirectional composite material is a fundamental parameter for the elastic characterization of composite laminates. For the purposes of design, the shear stress-strain response and the shear strength are also required. Of the many available test methods for determining the shear response of composite materials, Lee and Munro [1] have ranked the $10^{\circ}$ off-axis [2-5], the $\pm 45^{\circ}$ tensile test $[3,6,7]$ and the Iospisecu test method $[8-16]$ as the best test methods.

For the shear response obtained from each test method by Lee and Munro [1], strain gages are used to determine the average shear strain over the area of the specimen underneath the strain gages. The shear stress was assumed to be the average shear stress across the specimen's test section. Recent comparisons of the $10^{\circ}$ off-axis, the $\pm 45^{\circ}$ tensile test and the Iosipescu test method for graphite-epoxy composites have shown that each test 
method does not produce identical shear responses $[12,14]$. The discrepancy between the responses obtained from the three test methods applied to the same material has been ascribed to the lack of uniformity of the strain fields in the test sections $[12,14]$. The differences in the shear strengths obtained in each test method is thought to be due to the strain field nonuniformity and the varying degrees of purity of the shear as a result of the test method and the material properties [15]. The shear response from these tests was the average shear stress on a cross-section of the specimen plotted as a function of the shear strain computed from a strain gage rosette. However, the strain gage typically covers a small portion of the specimen's test section. Thus the response is only meaningful if the shear strain field is uniform.

In the present investigation, a comparison of three shear tests $\left(10^{\circ}\right.$ off axis, $\pm 45^{\circ}$ tensile and Iosipescu) was performed to evaluate the shear moduli of a graphite-epoxy composite material. These specimens were instrumented with strain gages on one surface and moire grating on the opposite surface. As well as allowing a comparison of the strains on the opposite surfaces of the specimens, moire interferometry provided a means for assessing the purity and uniformity of the shear strain fields in the specimen test sections.

\section{EXPERIMENTAL INVESTIGATION}

\section{Moire Interferometry}

Moire interferometry [17] is an optical method for measuring the in-plane surface horizontal (u) and vertical (v) displacement components of a specimen subjected to a load. The technique employs a high frequency crossed-line grating which is attached to the surface of the specimen and deforms with the specimen surface. The interference of two coherent light beams diffracted from the deformed specimen produces moire fringe patterns corresponding to the $u$ and $v$ fields. The sensitivity ( $f$ ) of the technique is determined by the frequency of the specimen grating, the wavelength of the light $(\lambda)$ and the optical arrangement. The basic equation is,

$$
f=\frac{2}{\lambda} \sin \alpha
$$

where $\alpha$ is the angle between the incident beam and the first order diffracted beam. The displacement components $u$ and $v$ are obtained from the fringe order $N_{x}$ and $N_{y}$ by 


$$
\mathrm{u}=\frac{1}{\mathrm{f}} \mathrm{N}_{\mathrm{x}} \quad \text { and } \quad \mathrm{v}=\frac{1}{\mathrm{f}} \mathrm{N}_{\mathrm{y}}
$$

and the in-plane strains by

$$
\begin{aligned}
& \varepsilon_{x}=\frac{\partial u}{\partial x}=\frac{1}{f} \frac{\partial N_{x}}{\partial x} \\
& \varepsilon_{y}=\frac{\partial v}{\partial y}=\frac{1}{f} \frac{\partial N_{y}}{\partial y} \\
& \gamma_{x y}=\frac{\partial u}{\partial y}+\frac{\partial v}{\partial x}=\frac{1}{f}\left(\frac{\partial N_{x}}{\partial y}+\frac{\partial N_{y}}{\partial x}\right)
\end{aligned}
$$

The crossed-line diffraction gratings that were applied to the surface of the specimens had a frequency of 1200 lines $/ \mathrm{mm}$, and covered the width of each specimen and extended approximately $30 \mathrm{~mm}$ lengthwise. The three-mirror interferometer which was used in the moire experiments was developed by Czarnek [18], and gave a fringe pattern sensitivity of $0.417 \mathrm{~mm}$ per fringe $(\mathrm{f}=2400$ lines $/ \mathrm{mm})$.

\section{Materials and Specimen Dimensions}

A unidirectional 20-ply graphite-epoxy panel was fabricated from AS4/3501-6 preimpregnated tape. The $10^{\circ}$ off-axis, $\pm 45^{\circ}$ tensile test and Iosipescu specimen dimensions used in the experimental program are shown in Fig. 1. Details about the location of the strain gage rosettes and locations of the moire gratings are also shown in Fig.1. The Iosipescu specimens were prepared with the fibers oriented in either the $0^{\circ}$ or $90^{\circ}$ directions, as indicated in Fig. 1c. The dimensions of the Iosipescu specimens corresponded to the modified Wyoming test fixture $[10,15]$.

\section{Specimen Testing, Instrumentation and Data Reduction}

The instrumented specimens were tested in a conventional screw driven test machine. The three-miror interferometer was positioned in front of the specimen. Before applying load to the specimen, the interferometer was tuned to provide no-load (null field) fringe pattems. The null field fringe patterns consisted of one fringe or less across the field of view. Load was then applied to the specimen until a predetermined value was obtained. Under constant loading, $u$ and $v$ fringe patterns were recorded photographically. This test procedure was repeated at numerous load levels until the fringe patterns became too dense to analyze. 
The strain gage data were recorded using a computer controlled data acquisition system. For each of the different shear specimens, the average shear stress was calculated in the appropriate coordinate system. Strain gage data were reduced to shear strains at the center of the test section.

For the $10^{\circ}$ off-axis specimen:

$$
\begin{aligned}
\tau_{12}^{\text {ave }} & =\sin 10^{\circ} \cos 10^{\circ} \frac{P}{A}=0.171 \frac{P}{A} \\
\gamma_{12} & =2 \sin 10^{\circ} \cos 10^{\circ}\left(-\varepsilon_{x}+\varepsilon_{y}\right)+\left(\sin ^{2} 10^{\circ}-\cos ^{2} 10^{\circ}\right) \gamma_{x y} \\
& =0.342\left(-\varepsilon_{x}+\varepsilon_{y}\right)-0.940 \gamma_{x y}
\end{aligned}
$$

where $P$ is the applied load and $A$ is the specimen cross-sectional area. Subscripts 1 and 2 refer to the fiber and in-plane normal to the fiber directions, respectively. Note that the shear stress expression in equation (4) does not take into account the end constraint effect [4]. In the calculation of the shear modulus, a correction factor has to be applied [4]. Pindera and Herakovich [4] suggested a correction factor given by

$$
\begin{aligned}
& C F=\left[1-\left[\beta\left(\sin ^{2} \theta-\cos ^{2} \theta\right)\right] / \sin \theta \cos \theta\right] /(1-2 \eta / 3), \\
& \beta=-\left[6(h / l)^{2} \overline{\left(\overline{S_{16}} / \overline{S_{11}}\right)}\right] /\left[1+6(h / l)^{2}\left(\overline{S_{66}} / \overline{S_{11}}\right)\right] \\
& \eta=-\beta\left(\overline{S_{16}} / \overline{S_{11}}\right)
\end{aligned}
$$

where $h$ and $l$ are the half-width and length of the specimen, respectively, $\theta$ is the angle between the fibers orientation and the $x$-axis, and $\overline{S_{11}}$ 's are the components of the reduced transformed compliant matrix. For the specimen geometry employed in the present study $(1 / 2 \mathrm{~h}=19.7)$, and assuming material properties $\mathrm{E}_{11}=138 \mathrm{GPa}, \mathrm{E}_{22}=8.96 \mathrm{GPa}, v_{12}=0.3$, and G12=7.1 GPa for AS4/3501-6 [19], the correction factor is 0.959 .

For the $\pm 45^{\circ}$ tensile specimen:

$$
\tau_{12}^{\text {ave }}=\sin 45^{\circ} \cos 45^{\circ} \frac{\mathrm{P}}{\mathrm{A}}=0.5 \frac{\mathrm{P}}{\mathrm{A}}
$$




$$
\begin{aligned}
\gamma_{12} & =2 \sin 45^{\circ} \cos 45^{\circ}\left(-\varepsilon_{x}+\varepsilon_{y}\right)+\left(\cos ^{2} 45^{\circ}-\sin ^{2} 45^{\circ}\right) \gamma_{x y} \\
& =\left(-\varepsilon_{x}+\varepsilon_{y}\right)
\end{aligned}
$$

For the Iosipescu shear specimen:

$$
\begin{aligned}
& \tau_{12}^{\text {ave }}=\frac{1}{h} \int_{b / 2}^{b / 2} \tau_{x y} d y \\
& \gamma_{12}=\gamma_{x y}=\left(E_{S G 1}-\varepsilon_{S G 2}\right)
\end{aligned}
$$

where $h$ is the distance between the notch roots and $\varepsilon_{\mathrm{SG} 1}$ and $\varepsilon_{\mathrm{SG} 2}$ are the normal strains recorded in the $\pm 45^{\circ}$ gages as shown in Fig. 1. The correction factor for the Iosipescu shear specimen is the ratio of the shear strain determined from the strain gage rosette to the average shear strain across the test section and depends upon the material system (primarily the orthotropy ratio) and fibers orientation [12,15,20,21]. Approximately, the correction factors can be expressed as [21],

$$
\mathrm{CF}=1.036-0.125 \times \log \left(\frac{\mathbf{E}_{\mathbf{x}}}{\mathbf{E}_{\mathbf{y}}}\right)
$$

where $E_{x}$ and $E_{y}$ are extensional stiffnesses in the longitudinal and transverse directions, respectively. For AS4/3501-6, the authors [21] have determined correction factors using the finite element technique, obtaining values of 0.87 and 1.19 for the $0^{\circ}$ and $90^{\circ}$ fiber orientations, respectively.

\section{RESULTS AND DISCUSSION}

\section{$10^{\circ}$ Off-axis Test}

The moire fringe data were used to determine shear strains over a region equivalent to that of the strain gage rosette which was attached to the opposite face of the specimen. A comparison of the shear stress-strain response on the front and back faces of the specimen is shown in Fig. 2. Because the purpose of this research is to evaluate the effect of different testing methods on the measured shear modulus, the shear stress-strain data are plotted up to $0.5 \%$ shear strain to render clear comparison between the three testing 
methods. The inconsistency of the front and back shear stress-strain curves in Fig. 2 is suspected to be caused by improper loading. That is, the specimen-to-test machine clamping method allows a small amount of play permitting small rotations about the $x$ - and $y$-axes of the grips. This play causes a small misalignment of the top and bottom grips which introduces out-of-plane bending and twisting. Typical moire fringe patterns for the $10^{\circ}$ off-axis specimen are shown in Fig. 3. The data in Fig. 3a indicate that the horizontal displacement field $u(x, y)$ on the surface of the specimen is uniform. That is, the fringes are generally straight, parallel and uniformly spaced except at the long edges where defects in the replicated grating occur. The moire data in Fig. $3 \mathrm{~b}$ represent the vertical component of displacement $v(x, y)$ on the surface of the specimen. The $v$-displacement field is not uniform. From left to right, the fringes go upward on the upper part of the specimen but go downward on the lower part of the specimen. This introduces negative $\partial v / \partial x$ on the upper and positive $\partial v / \partial x$ on the lower portions of the specimen.

The normal and shear strains across the width of the $10^{\circ}$ off-axis specimen were computed from the moire data using Equations 3 and transformed to the material axis system 1-2. The strain distributions are presented in Fig. 4 for three locations, $y=0$, the horizontal center-line of the specimen, and $y= \pm w$, where $w$ is the width of the specimen. The normal strain $\varepsilon_{1}$ is of small magnitude and is uniform across most of the specimen, but there is a variation of about $20 \%$ between the strains values for the three horizontal lines along which the data were obtained. The normal strain $\varepsilon_{2}$ is about $50 \%$ of the shear strain at the center of the specimen. Significant variations of $\varepsilon_{2}$ across the section ( $46 \%$ for $y=0$ ) and with the location y are also observed. The nonuniform distribution of $\varepsilon_{2}$, as can be observed in the moire fringes in Fig. 3, could be caused by material nonuniformity in the specimen or uneven clamping between the top and bottom grips. The shear strains $\gamma_{12}$ are also not uniform in the region covered by the moire grating. There are large variations in $\gamma_{12}$ from one edge of the specimen to the other and between the three $y$ locations. At $y=+w$, the variation in $\gamma_{12}$ across the width of the specimen is $16 \%$ while at $y=0$ and $y=-w$, the variations are $12 \%$ and $9 \%$ respectively. The variation of averaged $\gamma_{12}$ at $y=0$ and $y= \pm w$ is $3.8 \%$. The normal strain $\varepsilon_{2}$ and the shear strain $\gamma_{12}$ at one of the specimen long edges are higher than those at the center, thus failure may initiate from specimen edges.

\section{$\pm 45^{\circ}$ Tensile Test}

The shear stress-strain responses based on the moire and strain gage data from the front and back faces of the specimen are shown in Fig. 5. The moire fringe patterns are shown in Fig. 6. The horizontal component of the surface displacement field $u(x, y)$ 
consists of a uniform component together with a nonuniform displacement in bands at $45^{\circ}$ to the loading direction. A nonuniform displacement associated with the free edges of the specimen is observed. The vertical component of the surface displacement field $v(x, y)$ is represented by closely spaced almost horizontal fringes in Fig. $6 \mathrm{~b}$. There is also a nonuniform component of $v(x, y)$ displacement associated with the surface fibers, however, it is not as apparent as that in the $u$-displacement field. The uniform component of the displacement field can be removed optically [18]. This technique was used to produce the moire pattern shown in Fig. 7 in which the nonuniform component of the v-displacement field can be clearly correlated with the fiber directions. The bands of relatively large deformation are thought to be associated with resin rich regions between the reinforcement tows of the graphite-epoxy tape prepreg.

The strains were determined from the moire fringe patterns using Equations 3 and transformed to obtain the components in the material coordinate system 1-2. The normal and shear strain distributions across the width $w$ of the specimen are presented for two horizontal lines, $y=0$ and $y=0.5 \mathrm{w}$, in Fig. 8. The normal strains $\varepsilon_{1}$ and $\varepsilon_{2}$ are of small magnitude and are quite uniform across the specimen width at $y=0$ and $0.5 \mathrm{w}$ except at the free edges. As expected, the normal strains are equal. The presence of the free-edge effect is also apparent in the normal strain distributions as denoted by the abrupt change in strain values near the free edges. The longitudinal normal strain $\varepsilon_{\mathrm{x}}$ is negative in most of the field due to Poisson contraction except at the specimen long edges where $\varepsilon_{\mathbf{x}}$ is tensile. The shear strain $\gamma_{12}$ distribution does appear to vary with $y$, as shown in Fig. 8c. The difference between the shear strains at the center of the specimens at $y=0$ and $0.5 \mathrm{w}$ is approximately $10 \%$. It should be noted that strain gage rosettes measure average strains over the area of the rosette, therefore the shear strains determined from strain gages could differ by $5 \%$ at the center of the specimen for $y=0$ and $0.5 \mathrm{w}$. The differences in strains are attributed to material nonuniformity at the fiber tow level.

\section{Iosipescu Shear Test}

Two fiber orientations $0^{\circ}$ and $90^{\circ}$ were tested. The moire and strain gage data were used to obtain the shear stress-strain responses shown in Figs. 9 and 10 for the $0^{\circ}$ and $90^{\circ}$ specimens, respectively. The front and back face responses are the same for the $0^{\circ}$ specimen but are different for the $90^{\circ}$ specimen. The difference in shear strains on the faces of the $90^{\circ}$ specimen is related to specimen twisting about the $x$ axis [15]. On one face of the specimen the effects of twisting are additive whereas on the other face they are subtractive. Therefore the average of the front and back face responses can be used in 
determining the shear modulus. It should be noted that the difference between the front and back face response is systematic, that is, the shear strains measured on the face farthest away from the fixture's linear bearing (the front face) are always higher than those on the back face. Therefore, if a $90^{\circ}$ specimen was tested and a single strain gage rosette was applied then significant error could be realized.

Typical moire fringe patterns for the $0^{\circ}$ specimen are shown in Fig. 11. The horizontal displacement field $u(x, y)$ is represented in Fig. 11a. The very low fringe gradients in the horizontal $(x)$ direction are consistent with the high bending stiffness of the specimen with the $0^{\circ}$ fiber orientation. A pure and uniform shear field in the test section of the specimen would be represented in the vertical displacement field as a series of uniformly spaced vertical straight contours. In Fig. $11 \mathrm{~b}$ it is shown that the fringes are Sshaped so that there is some normal strain $\varepsilon_{y}\left(\varepsilon_{2}\right)$ in the test section due to the proximity of the applied loads to the test section $[15,20,21]$. It has been shown $[15,21]$ that this load proximity effect in the $0^{\circ}$ specimen causes the magnitudes of the strains in gages SGI and SG2, Fig. 1c, to be different but does not affect the shear strain calculation.

The moire fringe patterns for the $90^{\circ}$ specimen are shown in Fig. 12. The horizontal displacement field $u(x, y)$, represented by the fringe pattern in Fig. 12a, contains significant in-plane bending which is due to the low extensional stiffness $E_{x}$ of the material. The vertical displacement field $v(x, y)$, represented by the fringe pattern in Fig. $12 \mathrm{~b}$, corresponds to pure and uniform shear in a region at the center of the test section.

\section{Comparison of Shear Stress-Strain Responses}

Typical shear stress-strain responses for the graphite-epoxy specimens tested in the $10^{\circ}$ off-axis, the $\pm 45^{\circ}$ tensile and the $0^{\circ}$ and $90^{\circ}$ Iosipescu methods are presented in Fig. 13a. Since the tests are performed on the same material it would be reasonable to expect each test method produce the same response. It is apparent in Fig. 13a that the responses are different and the shear moduli are also different. Even after allowing for the twisting of the $90^{\circ}$ Iospiescu specimen (by taking the average of the front and back surface shear strains) the shear modulus appears to be significantly lower than that in the other tests. The difference between the responses is attributed to the nonuniformity of the shear fields in the various tests. Recall that the shear stress-strain response is presented as the average shear stress across the specimen test section plotted as a function of the average shear strain under the strain gage rosette. 
Correction factors $[12,15,21]$ have been suggested to allow for the nonuniformity of the shear strain fields in the $10^{\circ}$ off-axis and the Iosipescu specimens by estimating average shear strain corresponding to the measured (local) shear strain. Unfortunately, these correction factors depend upon the material orthotropy ratio $[12,15,21]$ and, to a much lesser extent, upon the shear modulus itself [12]. When the appropriate correction factors are applied to the experimentally determined shear strains the corrected responses, shown in Fig. 13b, are obtained. The effect of these correction factors is to bring the responses of the $10^{\circ}$ off-axis, the $\pm 45^{\circ}$ tensile and the $0^{\circ}$ and $90^{\circ}$ Iosipescu specimens close together, at least in the initial stages of the response where linear behavior was assumed for the calculation of the correction factors. Note that the difference between the responses is not necessarily due to the different characteristics of the testing methods. Much of the difference can be attributed to the material nonuniformity in the specimen panel. For specimens cut from the same panel, there might be as much as $5 \%$ difference in specimen thicknesses (hence the fiber volume fraction and the shear resistance) for a well laid up panel. Lee et al. [14] have shown that the shear moduli for IM6/American Cyanamid 1806 obtained from the $\pm 45^{\circ}$ tensile and $10^{\circ}$ off-axis specimens are $4.0 \mathrm{GPa}$ and $4.5 \mathrm{GPa}$, respectively, and the corresponding coefficient of variations are $8.6 \%$ and $5.4 \%$, respectively. Abdallah and Gasgoine [13] determined a shear modulus of $4.54 \mathrm{GPa}$ with a standard deviation of $0.73 \mathrm{GPa}$ for $0^{\circ} \mathrm{AS} 4 / 3501-6$ Iosipescu specimens. Thus, shear responses can signigicantly vary between specimens from the same panel.

\section{CONCLUSIONS}

Moire interferometry has been used to determine the surface displacement fields in $10^{\circ}$ off-axis, $\pm 45^{\circ}$ tensile and $0^{\circ}$ and $90^{\circ}$ losipescu graphite-epoxy specimens.

Comparisons of the moire data on one face of the specimens with data from a strain gage rosette on the opposite face have been made. It has been shown that the shear stress-strain responses obtained by instrumenting only one face of the $90^{\circ}$ Iosipescu specimen could give erroneous results. The $0^{\circ}$ Iosipescu specimens did not suffer from front to back face shear strain variations. The shear strain fields in the test section of the specimens of three testing methods are not uniform. Correction factors could be applied to bring all responses together, within the limits of the material uniformity, which was itself documented in the moire fringe patterns. Ideally, the correction factor for $\pm 45^{\circ}$ tensile specimen is one. In addition to significant edge effects, the strain distributions in the test section away from edges are not uniform for the $\pm 45^{\circ}$ tensile specimen. Thus correction factors other than unity have to be applied. Because the test section of the $90^{\circ}$ Iosipescu specimen is under 
pure shear, and there is no presence of unpredictable free edge effect in this unidirectional composite, the $90^{\circ}$ losipescu specimen is recommended for accurate shear modulus measurement of the composite materials as long as the front and back shear responses are used and correction factor applied in determining the shear modulus.

\section{ACKNOWLEDGEMENTS}

The work reported here was supported by the US Army Aerostructures Directorate under NASA Research Grant NAG-1-1053. The authors would also like to express their gratitude to Drs. Robert Czamek and Joosik Lee of the Engineering Science and Mechanics Department at VPI\&SU for their assistance with the moire experiments. 


\section{REFERENCES}

1. Lee, S. and Munro, M., "Evaluation of In-plane Shear Test Methods for Advanced Composite Materials by the Decision Analysis Technique," Composites, 17 (1) : 13-22 (January 1986).

2. Chamis, C.C. and Sinclair, J.H.,"Ten-deg Off-axis Test for Shear Properties in Fiber Composites," Experimental Mechanics, 17 (9) : 339-346 (1977).

3. Chiao, C.C., Moore, R.L. and Chiao,T.T.,"Measurement of Shear Properties of Fibre Composites," Composites, 8 (3) : 161-169 (1977).

4. Pindera, M.J. and Herakovich,C.T.,"Shear Characterization of Unidirectional Composites with the Off-axis Tension Test," Experimental Mechanics, 26 (1) : 103-122 (1986).

5. Pagano, N.J.and Halpin, J.C.,"Influence of End Constraint in the Tesing of Anisotropic Bodies," Journal of Composite Materials, 2 (1) :18-31 (1968).

6. Petit, P.H.,"A Simplified Method of Determining the Inplane Shear Stress-Strain Response of Unidirectional Composites," ASTM STP 460, pp. 83-93 (1969).

7. Rosen, B.W., "A Simple Procedure for Experimental Determination of the Longindinal Shear Modulus of Unidirectional Composites," Journal of Composite Materials, 6: 552554 (1972).

8. Iosipescu, N., "New Accurate Procedure for Single Shear Testing of Metals," Journal of Materials, 2 (3): 537-566 (1967).

9. Walrath, D.E. and Adams, D. F., "The Iosipescu Shear Test As Applied to Composite Materials," Experimental Mechanics, 23 (1): 105-110 (1983).

10. Adams, D. F. and Walrath, D. E.,"Further Development of the Iosipescu Shear Test Method,"Experimental Mechanics , 27 (2): 113-119 (1987).

11. Adams, D. F. and Walrath, D. E.,"Current Status of the Iosipescu Shear Test Method," Journal of Composite Materials, 21 (6): 494-507 (June 1987).

12. Pindera, M. J., Choksi, G., Hidde, J. S. and Herakovich, C. T.,"A Methodology for Accurate Shear Characterization of Unidirectional Composites," Journal of Composite Materials, 21 (12): 1164-1184 (1987).

13. Abdallah, M. G. and Gascoigne, H. E., "The Influence of Test Fixture Design of Iosipescu Shear Test for Fiber Composite Material," Test Methods and Design Allowables for Fibrous Composites: 2 nd Vol., ASTM STP 1003, C. C. Chamis, Ed., pp. 231-260 (1989).

14. Lee, S., Munro, M. and Scott, R.F.,"Evaluation of Three In-plane Shear Test Methods for Advanced Composite Materials, " Composites, 21 (6) : 495-502 (1990). 
15. Morton, J., Ho, H., Tsai, M.Y. and Farley, G.L., " An Evaluation of the Iosipescu Specimen for Composite Materials Shear Property Measurement," Journal of Composite Materials, in press.

16. Sullivan, J. L., Kao, B.G. and Van Oene, H.,"Shear Properties and a Stress Analysis Obtained from Vinyl-ester Iosipescu Specimen," Experimental Mechanics, 24 (3): 223-232 (1984).

17. Guild, J.,"The Interference Systems of Crossed Diffraction Gratings; Theory of Moire Fringes," Oxford at the Clardendon Press, (1956).

18. Czarnek, R.,"New Methods in Moire Interferometry," Ph.D. dissertation, VPI\&SU (1984).

19. Tsai, S. W. , "Composite Design," 4th edition, Appendix B, p B-2 (1988).

20. Ho, H., Tsai, M.Y., Morton, J. and Farley, G.L., " An Experimental Investigation Of Iosipescu Specimen For Composite Materials," Experimental Mechanics, 31 (4) : 328 336,1991 ..

21. Ho, H., Tsai, M.Y., Morton, J. and Farley, G.L., "Numerical Analysis Of The Iosipescu Specimen For Composite Materials," Composite Science and Technology, in review. 


\section{FIGURE TITLES}

Fig. 1 Test specimen dimensions for (a) $10^{\circ}$ off-axis, (b) $\pm 45^{\circ}$ tension, (c) Iosipescu specimens.

Fig. 2 Shear stresss-strain data on the front (moire) and back (strain gage rosette) faces for $10^{\circ}$ off-axis specimen.

Fig. 3 Typical (a) $u$-field and (b) v-field fringe patterns for the $10^{\circ}$ off-axis specimen at $\tau_{12}{ }^{\text {ave }}=3.96 \mathrm{MPa}$.

Fig. 4 Strain distributions (a) $\varepsilon_{1}$, (b) $\varepsilon_{2}$ and (c) $\gamma_{12}$ at $y=0$ and $y= \pm w$ (w=width of specimen), reduced from moire fringe contours for the $10^{\circ}$ off-axis specimen.

Fig. 5 Shear stress-strain data on the front (moire) and back (strain gage rosette) faces for $\pm 45^{\circ}$ tensile specimen.

Fig. 6 Typical (a) u-field and (b) v-field fringe patterns for the $\pm 45^{\circ}$ tensile specimen at $\tau_{12}{ }^{\text {ave }}=11.0 \mathrm{MPa}$.

Fig. 7 Non-uniformity of v-field fringe pattern for the $\pm 45^{\circ}$ tensile specimen at $\tau_{12} 2^{\text {ave }}=28.0$ $\mathrm{MPa}$.

Fig. 8 Strain distributions (a) $\varepsilon_{1}$, (b) $\varepsilon_{2}$ and (c) $\gamma_{12}$ at $y=0$ and $y=w / 2$ ( $w=w i d t h$ of specimen), reduced from moire fringe contours for the $\pm 45^{\circ}$ tensile specimen.

Fig. 9 Shear stress-strain data obtained from front (moire) and back (strain gage rosette) faces of the $0^{\circ}$ Iosipescu specimen.

Fig. 10 Shear stress-strain data obtained from front (moire) and back (strain gage rosette) faces of the $90^{\circ}$ Iosipescu specimen.

Fig. 11 Typical (a) $u$-field and (b) v-field fringe patterns for the $0^{\circ}$ Iosipescu specimen at $\tau_{12}{ }^{\text {ave }}=20.5 \mathrm{MPa}$.

Fig. 12 Typical (a) u-field and (b) v-field fringe patterns for the $90^{\circ}$ Iosipescu specimen at $\tau_{12}$ ave $=34.0 \mathrm{MPa}$.

Fig. 13 Typical shear stress-strain responses (a) before and (b) after the application of correction factors. Note that the end points of the shear stress-strain response curves do not indicate specimen failure. 


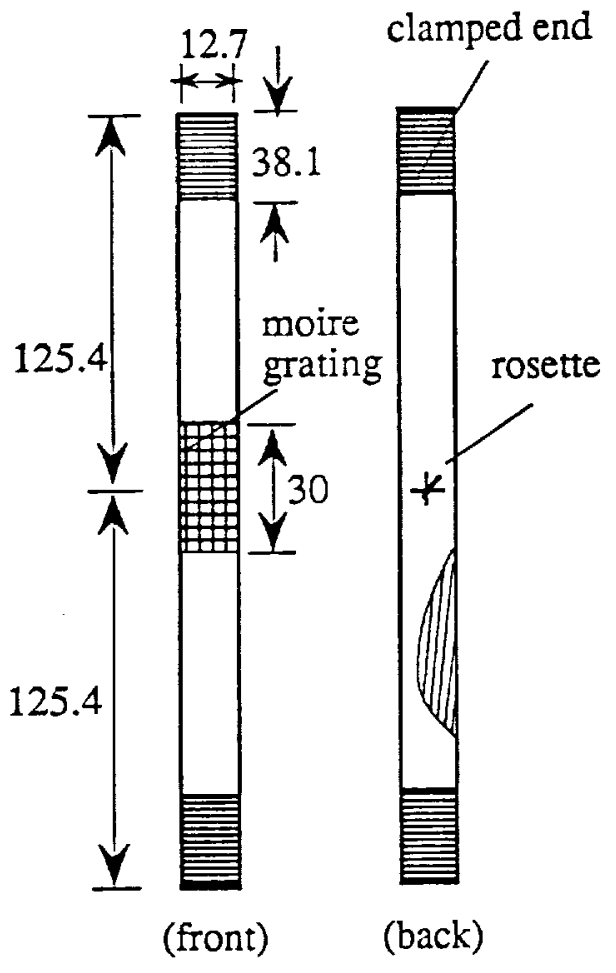

(a)

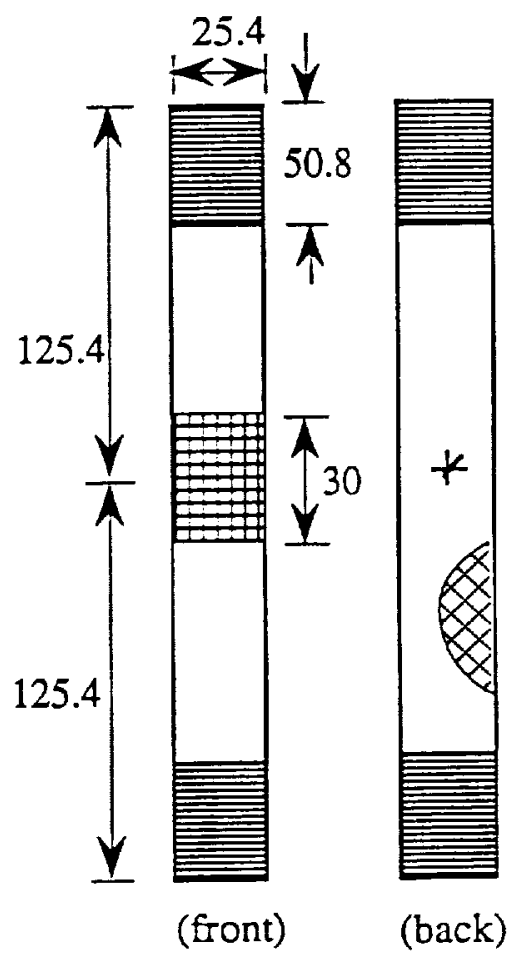

(b)

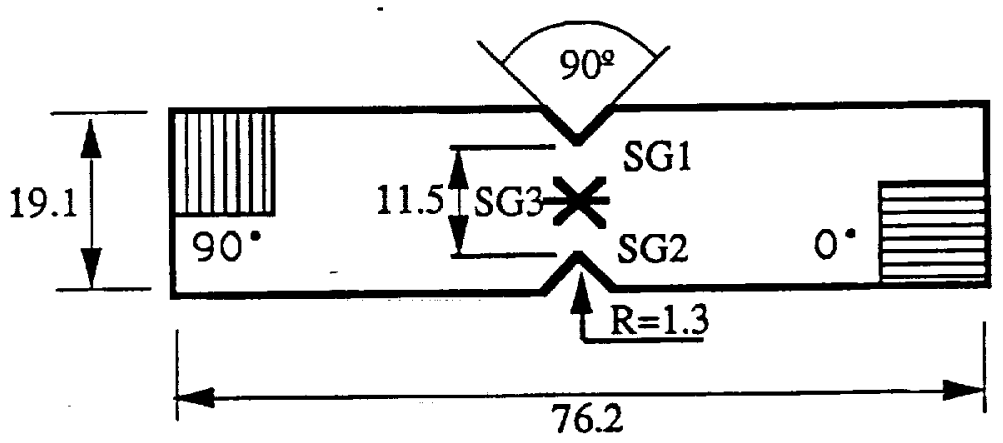

(c)

Fig. 1 Test specimen dimensions for (a) $10^{\circ}$ off-axis, (b) $\pm 45^{\circ}$ tension, (c) Iosipescu specimens. 


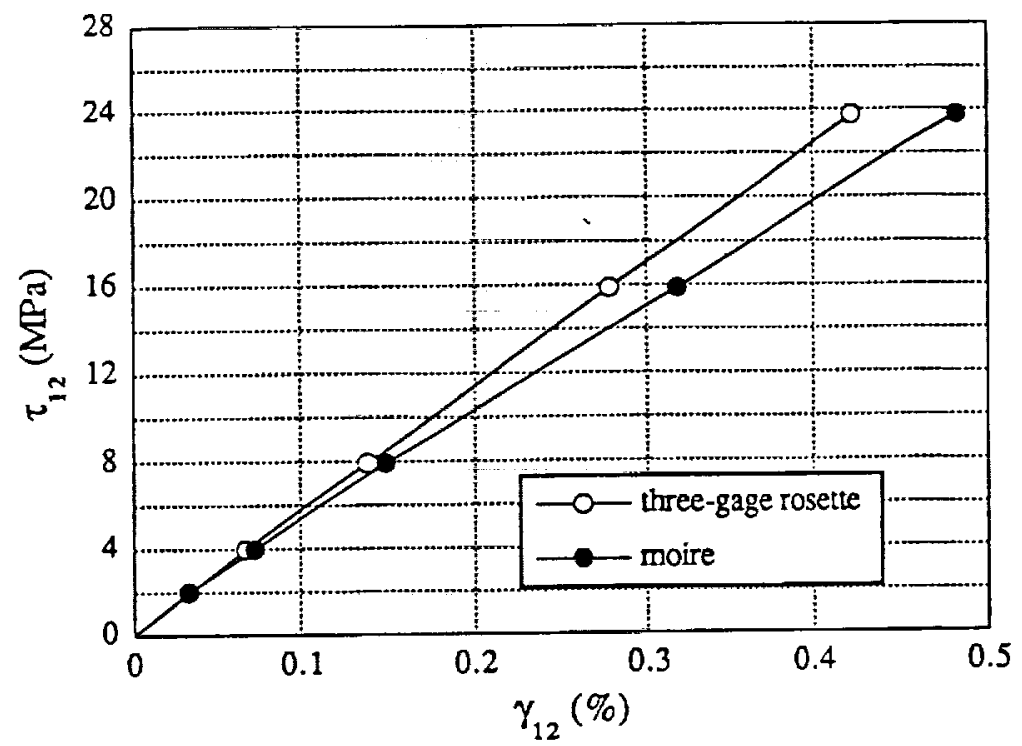

Fig. 2 Shear stress-strain data on the front (moire) and back (strain gage rosette) faces for $10^{\circ}$ off-axis specimen. 


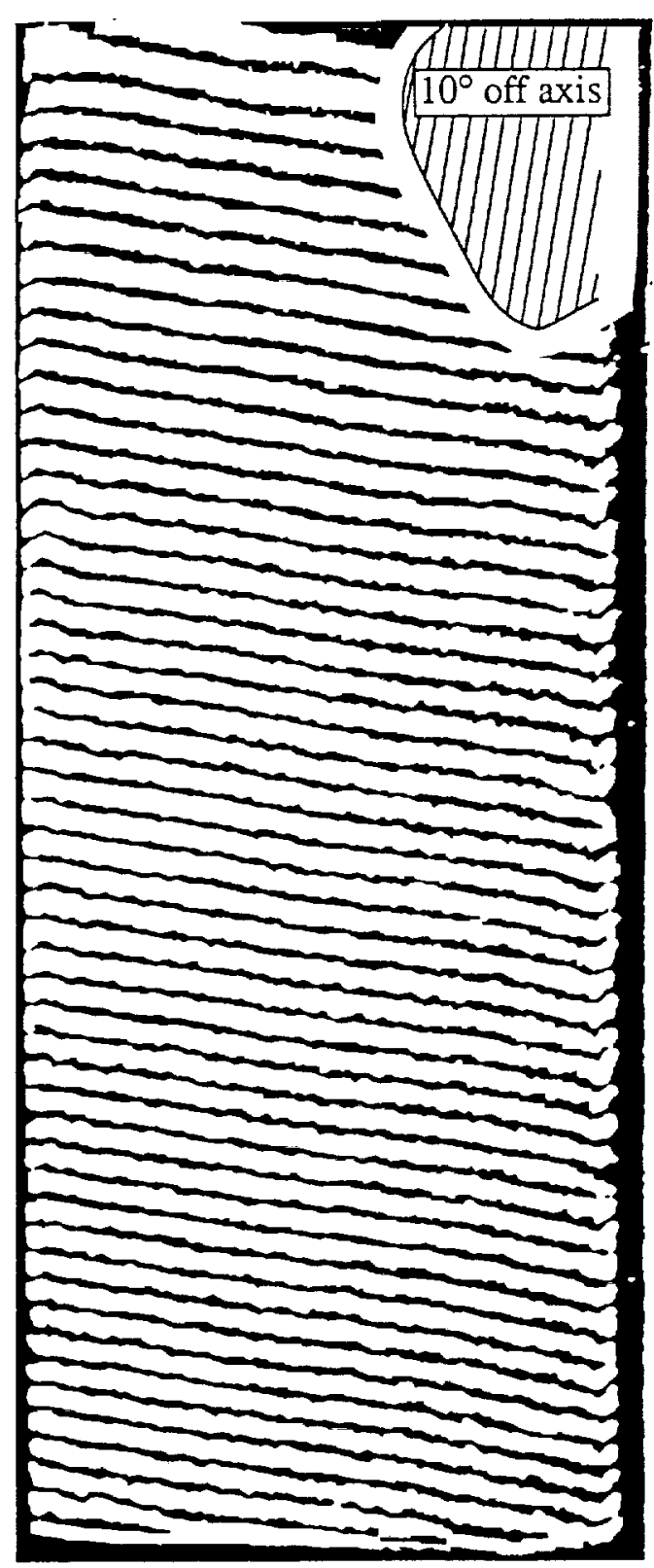

(a)

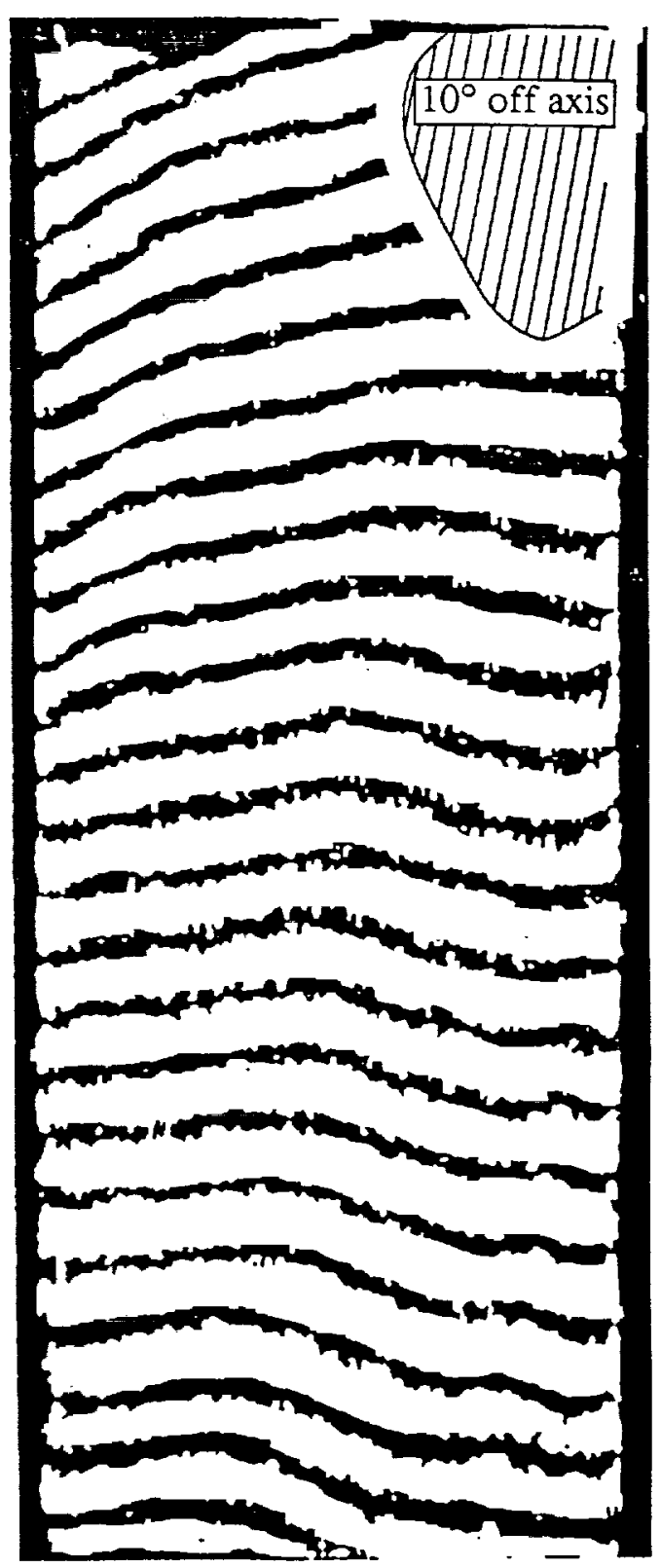

(b)

Fig. 3 Typical (a) u-field and (b) v-field fringe patterns for the $10^{\circ}$ off-axis specimen at ${ }^{\circ}$. $\tau_{12}$ ave $=3.96 \mathrm{MPa}$. 


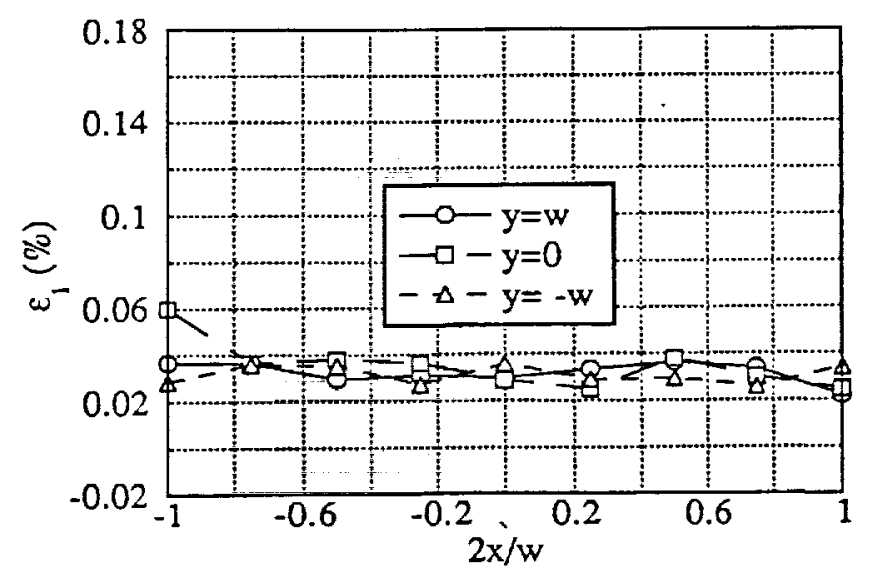

(a)

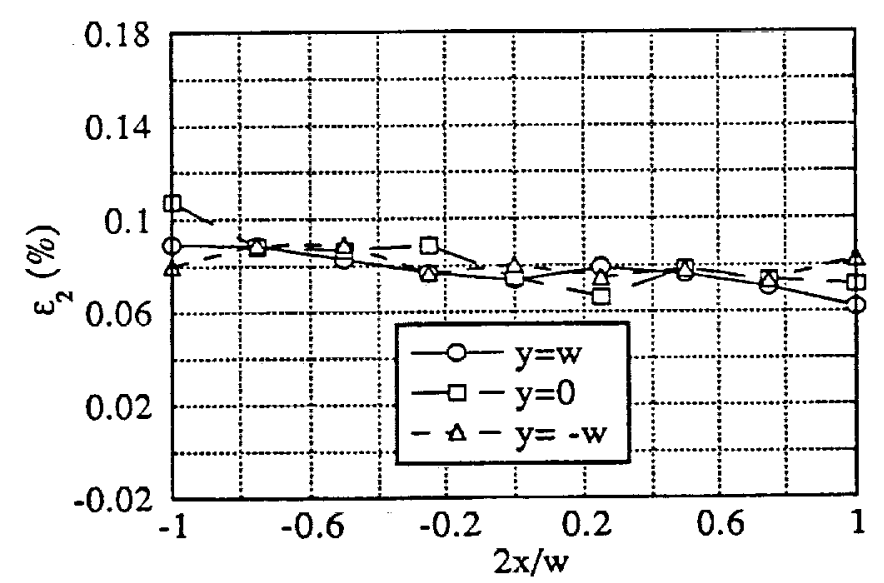

(b)

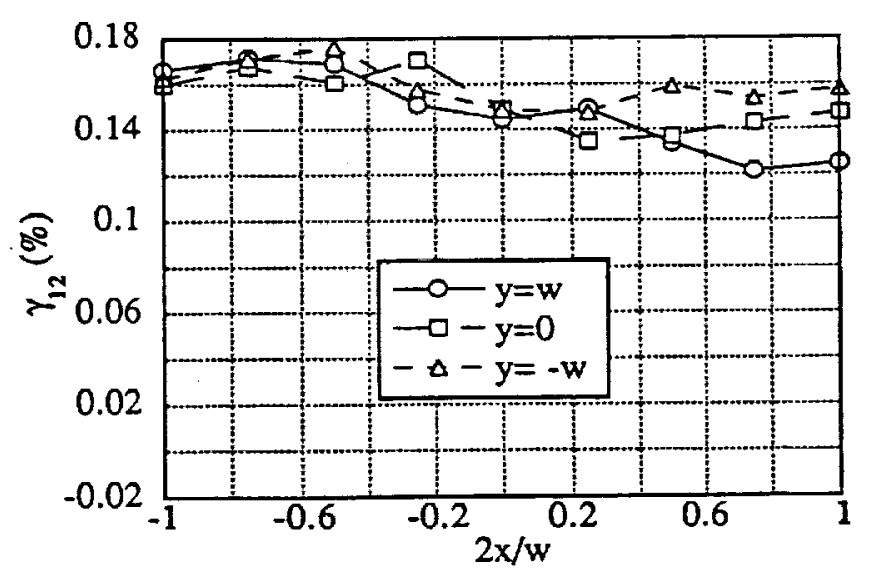

(c)

Fig. 4 Strain distributions (a) $\varepsilon_{1}$, (b) $\varepsilon_{2}$ and (c) $\gamma_{12}$ at $y=0$ and $y= \pm w$ ( $w=w i d t h$ of specimen), reduced from moire fringe contours for the $10^{\circ}$ off-axis specimen. 


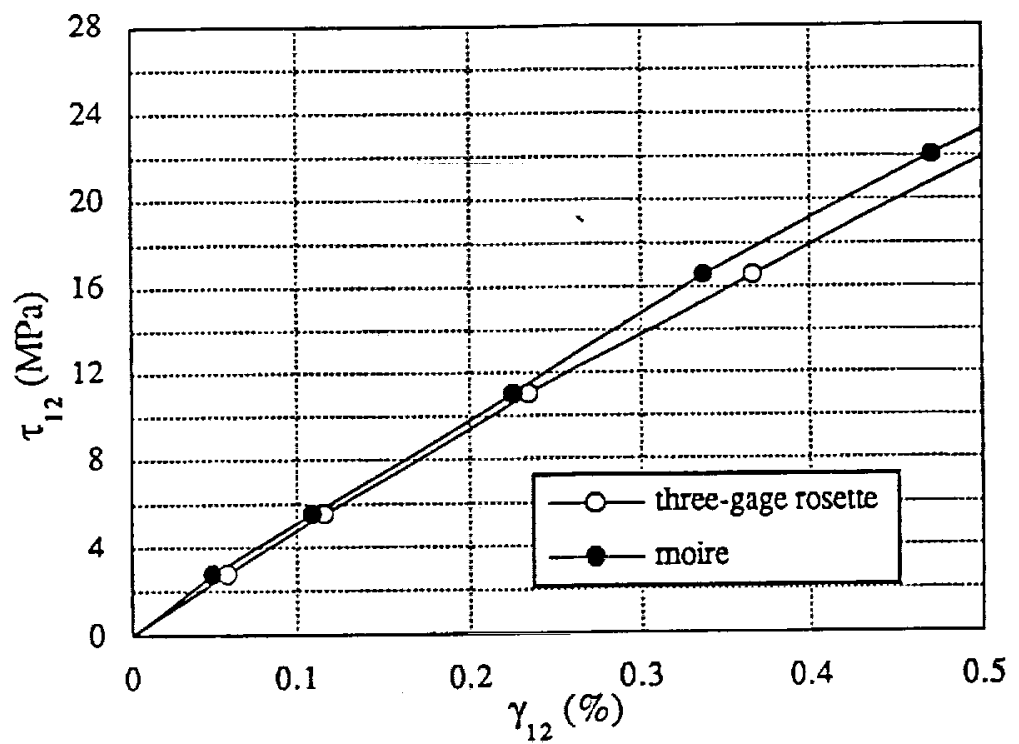

Fig. 5 Shear stress-strain data on the front (moire) and back (strain gage rosette) faces for $\pm 45^{\circ}$ tensile specimen. 


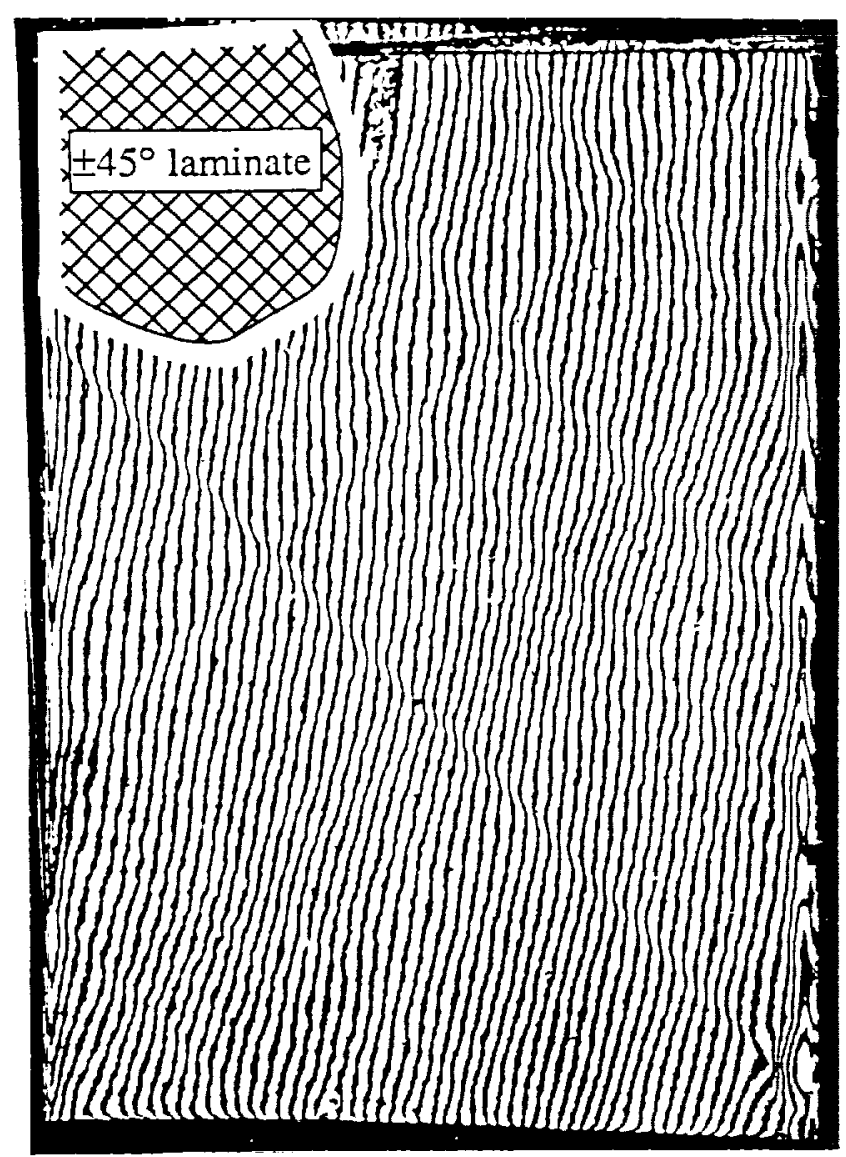

(a)

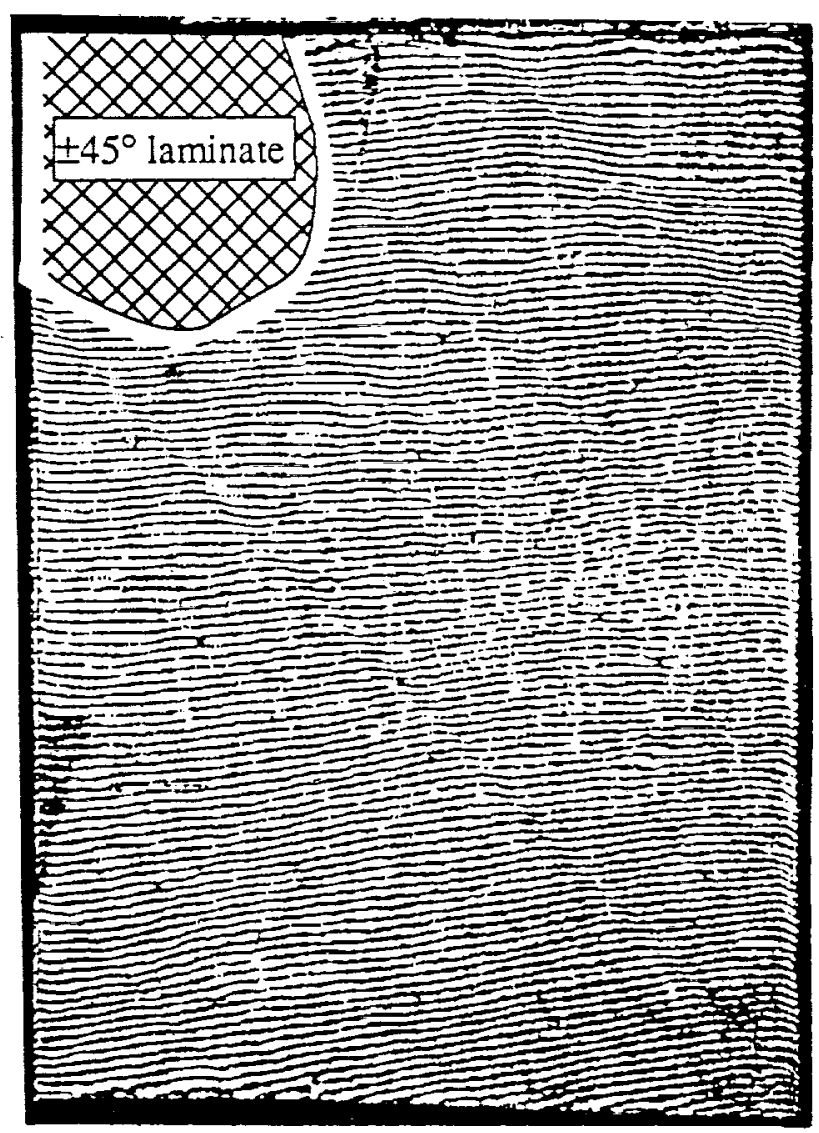

(b)

Fig. 6 Typical (a) u-field and (b) v-field fringe patterns for the $\pm 45^{\circ}$ tensile specimen at $\tau_{12}$ ave $^{\text {av }}=11.0 \mathrm{MPa}$. 


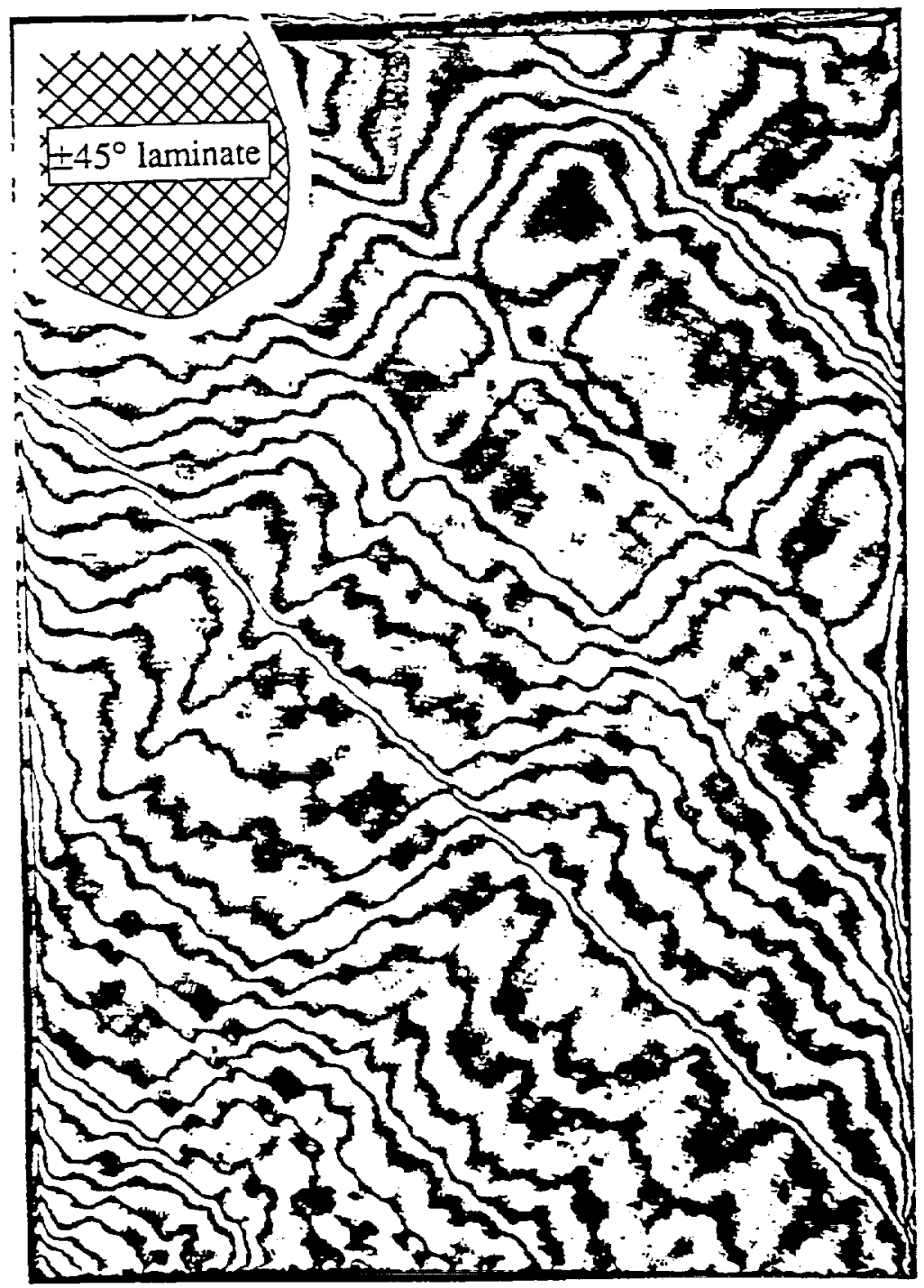

Fig. 7 Non-uniformity of $v$-field fringe pattern for the $\pm 45^{\circ}$ tensile specimen at $\tau_{12}{ }^{\text {ave }}=28 \mathrm{MPa}$. 


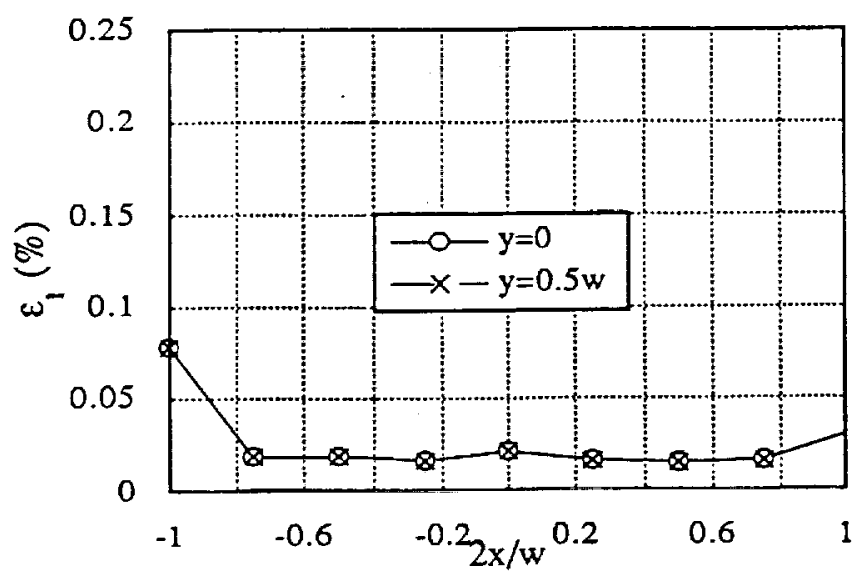

(a)
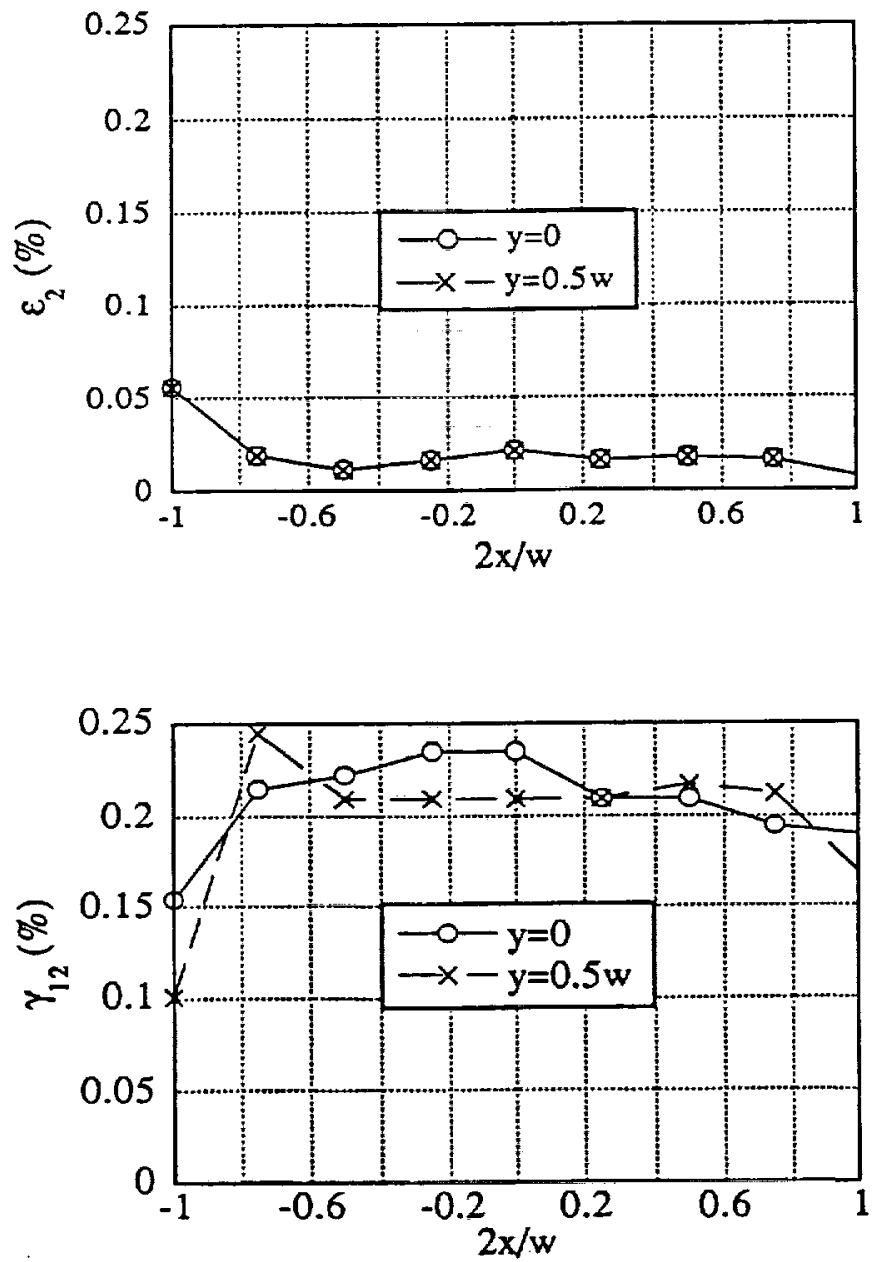

(c)

Fig. 8 Strain distributions (a) $\varepsilon_{1}$, (b) $\varepsilon_{2}$ and (c) $\gamma_{12}$ at $y=0$ and $y=w / 2$ (w=width of specimen), reduced from moire fringe contours for the $\pm 45^{\circ}$ tensile specimen. 


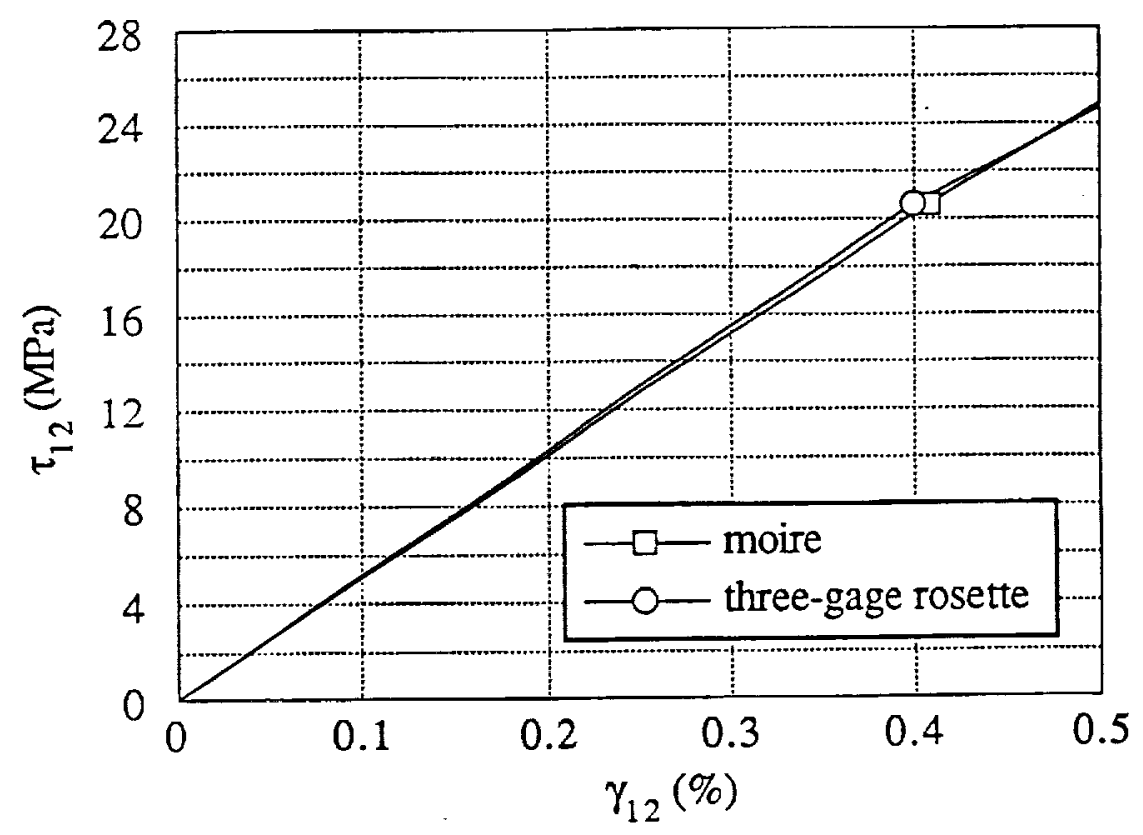

Fig. 9 Shear stress-strain data obtained from front (moire) and back (strain gage rosette) faces of the $0^{\circ}$ Iosipescu specimen. 


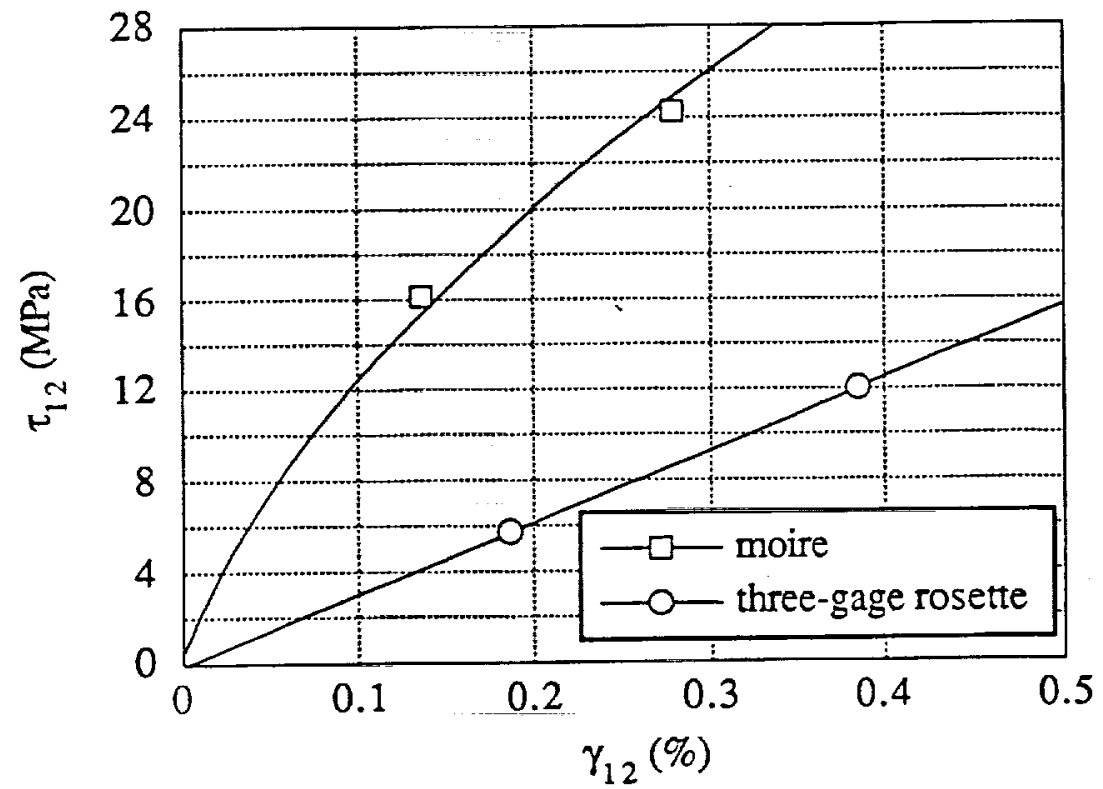

Fig. 10 Shear stress-strain data obtained from front (moire) and back (strain gage rosette) faces of the $90^{\circ}$ Iosipescu specimen. 

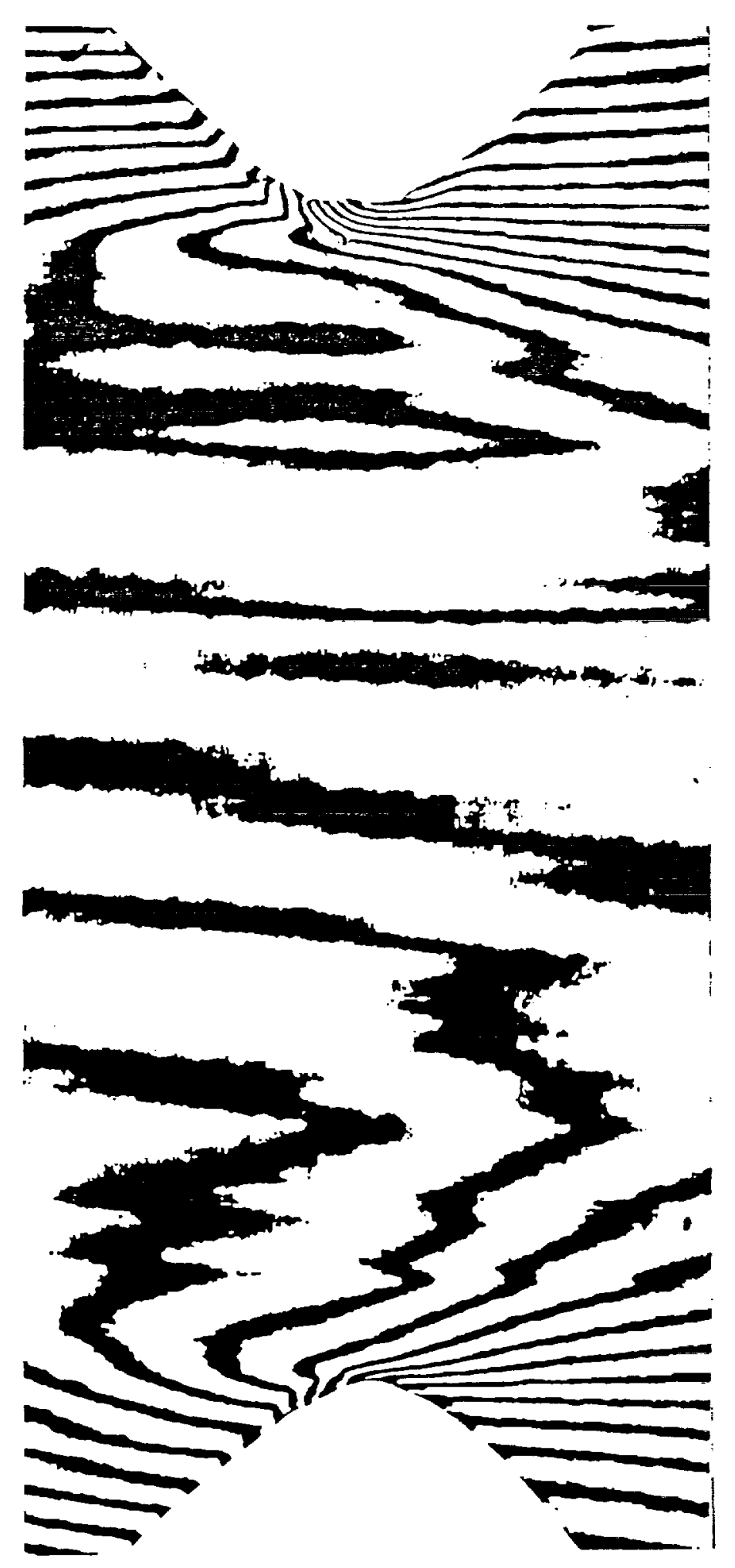

(a)

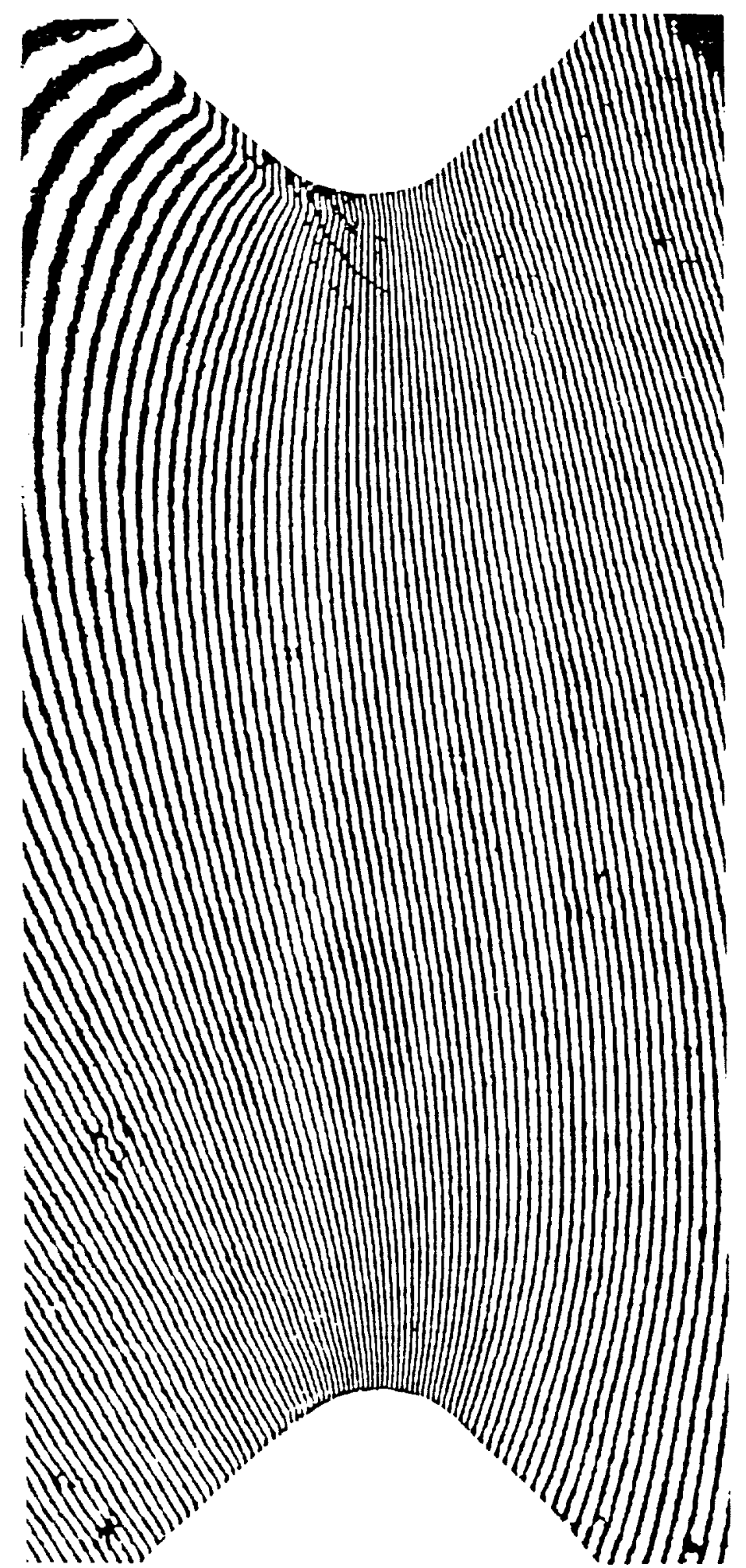

(b)

Fig. 11 Typical (a) $u$-field and (b) v-field fringe patterns for the $0^{\circ}$ Iosipescu specimen at $\tau_{12}{ }^{\text {ave }}=20.5 \mathrm{MPa}$. 


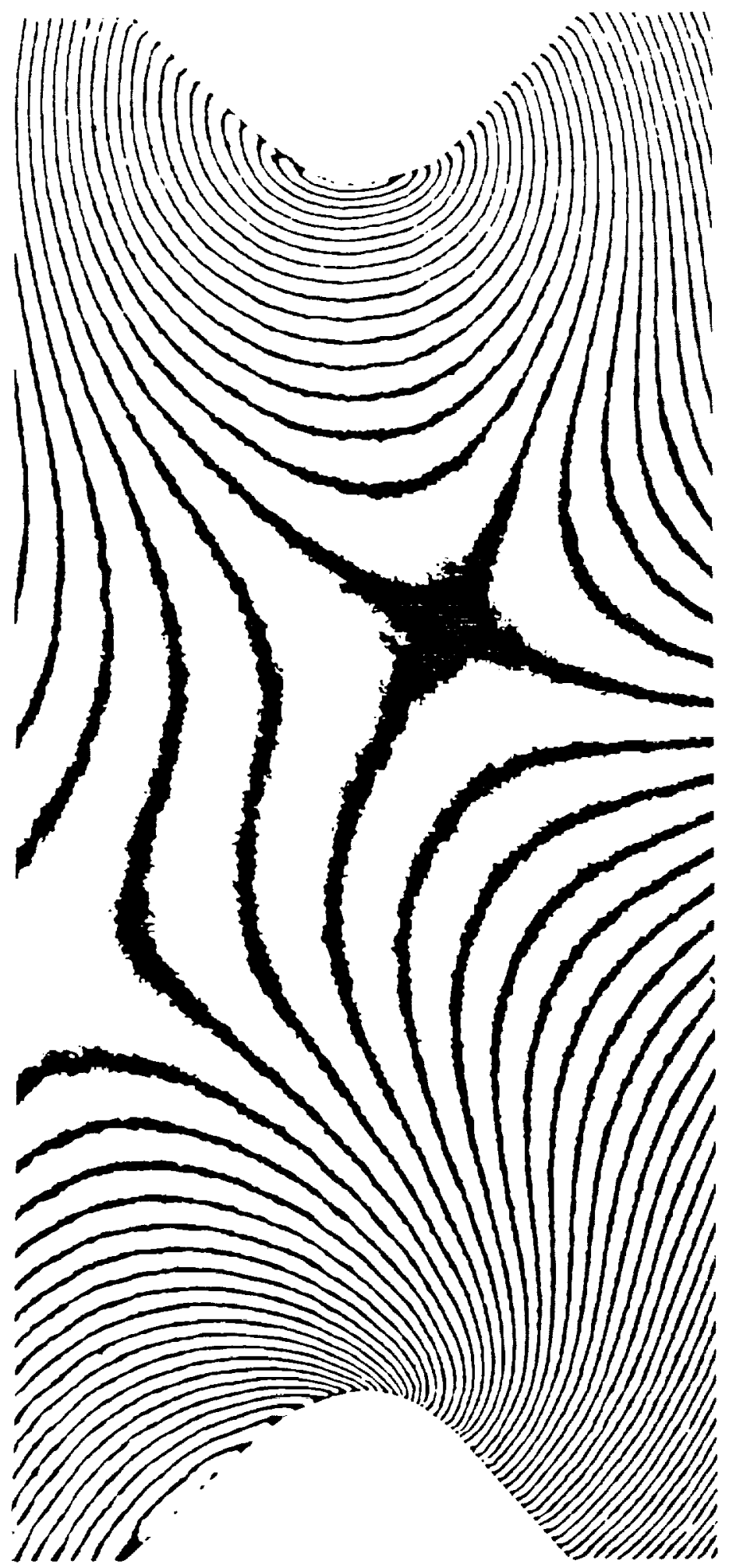

(a)

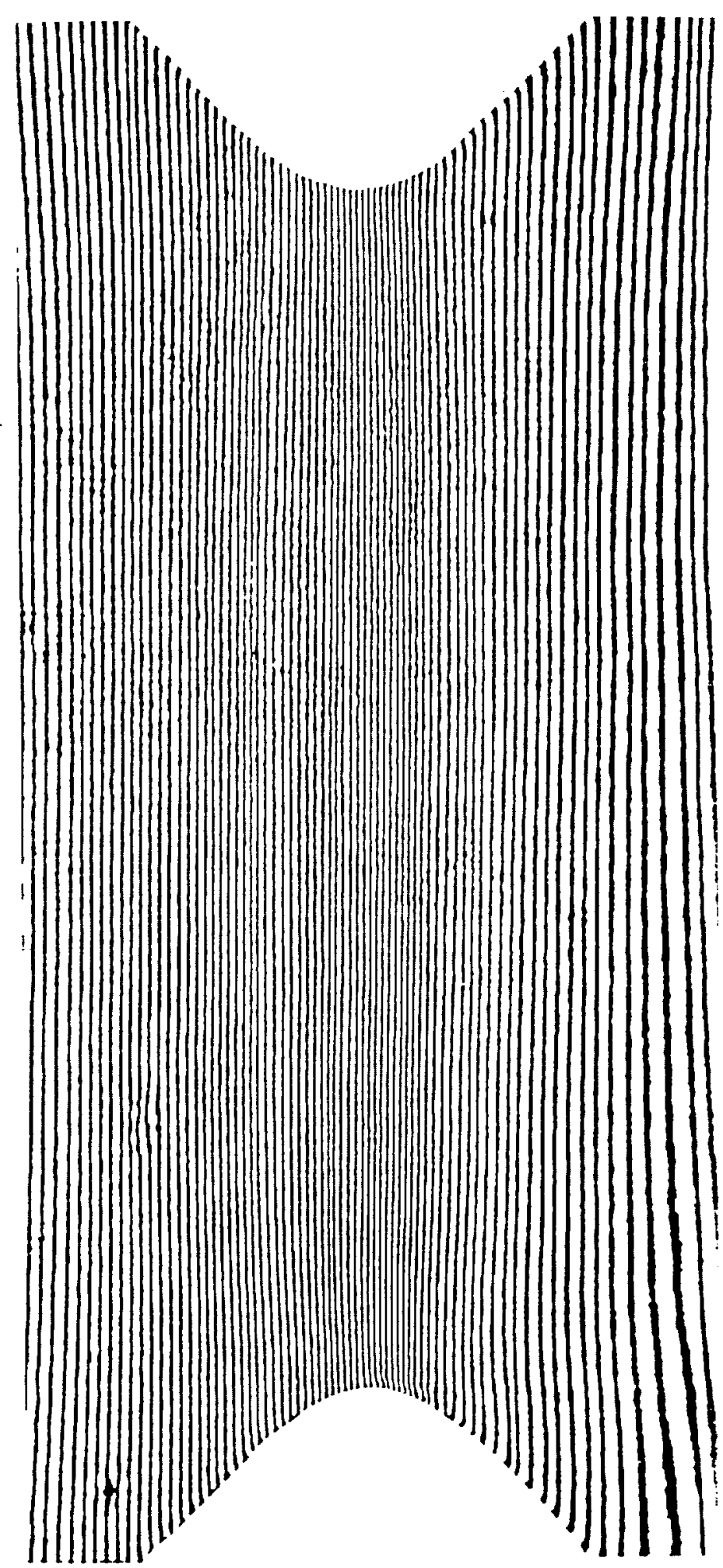

(b)

Fig. 12 Typical (a) u-field and (b) v-field fringe pattems for the $90^{\circ}$ Iosipescu specimen at $\tau_{12}{ }^{\text {ave }}=34.0 \mathrm{MPa}$. 


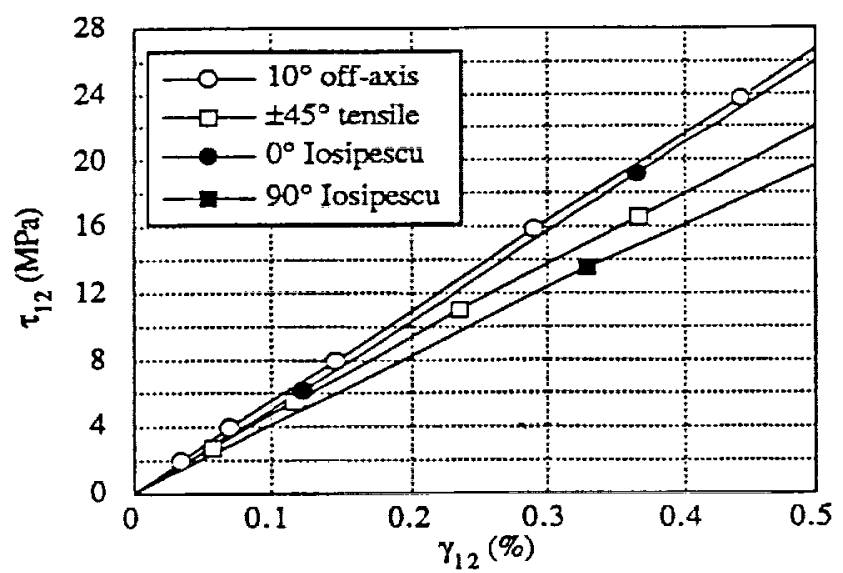

(a)

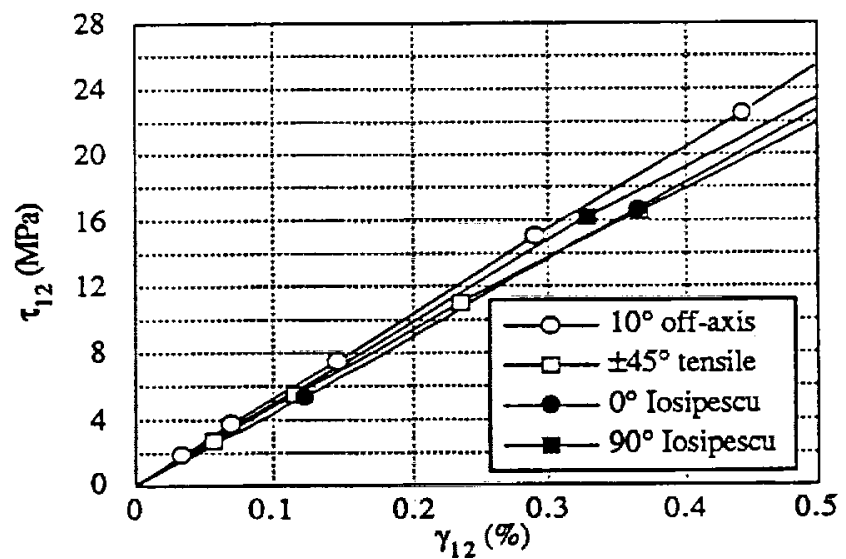

(b)

Fig. 13 Typical shear stress-strain responses (a) before and (b) after the application of correction factors. Note that the end points of the shear stress-strain response curves do not indicate specimen failure. 